\title{
choer
}

\section{Um olhar sobre a violência LGBTIfóbica no Brasil}

\section{Kalyne Alves Andrade Santos}

Mestranda em Direito pela Universidade Federal de Sergipe - UFS

ka.lyne@hotmail.com

\section{Karyna Batista Sposato}

Doutora em Direito pela Universidade Federal da Bahia - UFBA

Professora da Universidade Federal de Sergipe - UFS

karyna.sposato@pq.cnpq.br

\section{Resumo}

O objetivo deste artigo é analisar os dados de violência letal no Brasil contra a população sexodiversa, nos últimos 5 anos, a partir dos relatórios do Grupo Gay da Bahia (GGB) e da Comissão Interamericana de Direitos Humanos (CIDH). A elucidação e o esclarecimento acerca das concepções de homofobia, do heterossexismo e da heteronormatividade são meios de que dispomos para compreender a violência LGBTIfóbica presente na sociedade contemporânea. Os resultados obtidos indicam que, para o enfrentamento dessa violência, políticas públicas devem ser elaboradas como meios de superação dessa realidade.

Palavras-chave direitos humanos; violência; homofobia; LGBTI; LGBTIfobia.

\section{A look at LGBTIphobic violence in Brazil}

\begin{abstract}
This article aims at analyzing data on lethal violence in Brazil against the sex-diverse population, within the last 5 years, based on reports by the Gay Group of Bahia (Grupo Gay da Bahia - GGB) and the Inter-American Commission on Human Rights (IACHR). Elucidation and clarification on the concepts of homophobia, heterosexism, and heteronormativity are means that we have to grasp the LGBTIphobic violence observed in contemporary society. The results indicate that, in order to cope with violence, public policy must be made as a means to overcome such a reality.
\end{abstract}

Key words human rights; violence; homophobia; LGBTI; LGBTIphobia.

Conhecer: debate entre o público e o privado

2019, Vol. 09, no 22

ISSN 2238-0426

DOI 10.32335/2238-0426.2019.9.22.1014

Licença Creative Commons Atribuição (CC BY 4.0)

Data de submissão 07 fev 19

Data de publicação 22 abr 19 


\title{
Una mirada a la violencia LGBTIfóbica en Brasil
}

\author{
Resumen
}

El objetivo de este artículo es analizar los datos de violencia letal en Brasil contra la población sexodiversa, en los últimos 5 años, según los informes del Grupo Gay de Bahía (Grupo Gay da Bahia - GGB) y de la Comisión Interamericana de Derechos Humanos (CIDH). La elucidación y la aclaración de los conceptos de homofobia, heterosexismo y heteronormatividad son medios que tenemos para comprender la violencia LGBTIfóbica presente en la sociedad contemporánea. Los resultados indican que, para hacer frente a esta violencia, políticas públicas deben hacerse como medios para superar esta realidad.

Palabras clave derechos humanos; violencia; homofobia; LGBT; LGBTIphobia.

\section{Introdução}

A população constituída por lésbicas, gays, bissexuais, travestis, transexuais, pessoas trans e intersex (LGBTI) é um grupo vulnerável, alvo de inúmeras violações de direitos humanos em todo o mundo. No Brasil, ao longo dos últimos anos, situações de violência e discriminação contra a população LGBTI vêm ocorrendo com maior frequência e de maneira assustadora, inclusive resultando em recomendações da Comissão Interamericana de Direitos Humanos (CIDH) (Organización de los Estados Americanos [OEA], 2012a, 2012b, 2012c) para que o Estado brasileiro adote medidas para prevenir e responder aos abusos dos direitos humanos e garantir que as pessoas LGBTI exerçam seu direito a uma vida livre de discriminação e violência LGBTIfóbica, incluindo a adoção de políticas e campanhas públicas e as reformas necessárias para adequar as leis aos instrumentos interamericanos de direitos humanos.

O enfrentamento dos problemas relacionados à segurança pública representa um dos maiores desafios da América Latina e também da sociedade brasileira. Essa realidade pode ser percebida a partir de diversos indicadores encontrados, no Relatório da CIDH de $2015^{1}$ e no Atlas da Violência 2018 (Cerqueira et al., 2018), produzido pelo Instituto de Pesquisa Econômica Aplicada (IPEA) e pelo Fórum Brasileiro de Segurança Pública (FBSP).

$1 \quad$ O relatório da sobre violência contra pessoas lésbicas, gays, bissexuais, trans e intersexo nas Américas (Comissão Interamericana de Direitos Humanos [CIDH], 2015), identificou tendências gerais, como, por exemplo, a falta de denúncias e estatísticas oficiais, violência generalizada, invisibilidade da violência cotidiana, invisibilidade da violência contra certos grupos (homens trans, pessoas bissexuais e pessoas intersexo), além de altos níveis de crueldade e violência em represália a demonstrações públicas de afeto entre pessoas do mesmo sexo. 
No que diz respeito à população LGBTI, é o Grupo Gay da Bahia (GGB) ${ }^{2}$ que faz o levantamento dos índices de violência, produzindo anualmente relatórios sobre pessoas LGBTI mortas no Brasil. A análise dos dados referentes aos últimos 5 anos (Grupo Gay da Bahia [GGB], 2014, 2015, 2016, 2017, 2018) ilustra o quanto a violência vem crescendo gradualmente no país e aponta a urgência de políticas públicas para a superação desse quadro.

A questão com que nos defrontamos é em que ponto a LGBTIfobia da sociedade e do Estado brasileiro tem contribuído para a exacerbação da violência no Brasil. Buscar compreender as concepções em torno da homofobia, do heterossexismo e da heteronormatividade é um dos meios de que dispomos para compreender a violência LGBTIfóbica presente na sociedade contemporânea, bem como apontar meios para superar esse desafio.

\section{Violência letal LGBTIfóbica no Brasil}

O Atlas da Violência 2018 revela que o Brasil é um dos países mais violentos do mundo. Em relação à população transgênera, o Relatório da organização não governamental (ONG) Transgender Europe (TGEu) indica que o país ocupa a primeira posição no ranking mundial de países com mais assassinatos relacionados à transfobia (entre 2008 e 2016).

A intolerância, o preconceito, a discriminação e a violência em razão de orientação sexual e identidade de gênero tem reduzido drasticamente a expectativa de vida dessa população, por exemplo, a expectativa de vida do transexual é de 35 anos, ou seja, menos da metade da média brasileira, que é de 76 anos, segundo dados do Instituto Brasileiro de Geografia e Estatística (IBGE, 2018).

O levantamento dos relatórios do GGB reúne índices de violência contra a população LGBTI entre 2014 e 2018 e o perfil das vítimas. A análise desses dados demonstra como estamos e o que pode ser feito em termos de políticas públicas para o enfrentamento desse tipo de violência.

Em 2014, o relatório anual de assassinatos de homossexuais no Brasil indicou 326 mortes, incluindo 9 suicídios (GGB, 2014). Isso já representava um aumento de 4,1\% em relação ao ano de 2013.

Do total de homicídios, 163 vitimaram gays, 134 travestis, 14 lésbicas, 3 bissexuais e 7 amantes de travestis. Além dessas mortes, também foram assassinados 7 heterossexuais por terem sido "confundidos com gays ou por estarem em circunstâncias ou espaços homoeróticos” (GGB, 2014).

Em relação ao fator racial, $54 \%$ das vítimas eram brancas, $41 \%$ pardas e $5 \%$ negras. O que pode ser considerado uma tendência destoante do perfil de violência letal

2 O GGB é uma ONG e suas atividades são voltadas à defesa dos direitos dos homossexuais no Brasil. Fundada em 1980 e sediada em Salvador, é a associação brasileira de defesa da população LGBTI mais antiga. 
predominante no Brasil, já que, por exemplo, em 2014, a taxa de homicídios de negros por 100 mil habitantes era de 38,5\%, enquanto a de não negros era de 16,0\% (Instituto de Pesquisa Econômica Aplicada [IPEA], 2018).

Os dados referentes ao ano de 2015 revelaram que 318 pessoas LGBTI foram assassinadas no país (GGB, 2015). Nesse universo, $52 \%$ eram gays, $37 \%$ travestis, $16 \%$ lésbicas e $10 \%$ bissexuais.

É importante destacar que a violência homofóbica atinge uma pluraridade de identidades, atingindo do adolescente ao idoso, brancos e não brancos, além de todas as classes sociais.

O relatório apontou que 55\% das vítimas eram brancas e $45 \%$ negras. Isso destoa do perfil brasileiro de violência letal, onde a taxa de homicídios de negros por 100 mil habitantes no Brasil, em 2015, correspondeu a 37,7\%, enquanto a de não negros representou 15,3\% (IPEA, 2018).

Quanto à profissão das vítimas, 26 eram profissionais do sexo, 16 cabelereiras, 10 estudantes, 3 pais de santo, 2 pastores evangélicos, 1 padre católico, além de comerciários, funcionários públicos, advogados, bailarinos, moradores de rua (GGB, 2015).

Em 2016, 343 indivíduos LGBTI foram assassinados no Brasil. Isso representa 1 morte a cada 25 horas. Dos 343 assassinados, 50\% eram gays, 42\% trans, 3\% lésbicas e $1 \%$ bissexuais, incluindo 12 heterossexuais, como os amantes de transexuais (os chamados T-lovers) (GGB, 2016).

Quanto à cor dos indivíduos LGBTI assassinados, 64\% eram brancos e 36\% negros. Mais uma vez, o fator racial foge do padrão de violência letal predominante no país, uma vez que, em 2016, a taxa de homicídios de negros por 100 mil habitantes era de 40,2\%, enquanto a de não negros era de 16,0\% (IPEA, 2018).

O relatório de 2017 apontou que " 445 LGBT+ (lésbicas, gays, bissexuais e transexuais) morreram no Brasil (incluindo 3 nacionais mortos no exterior) vítimas da homotransfobia" (GGB, 2017). Dessas vítimas do preconceito e da discriminação, 387 foram assassinadas e 58 se suicidaram. Além disso, segundo o relatório houve um aumento de $30 \%$ em relação a 2016, quando se registraram 343 mortes (GGB, 2017).

Das 445 vítimas de homotransfobia documentadas em 2017, 43,6\% eram gays, 42,9\% trans, 9,7\% lésbicas, 1,1\% bissexuais e 2,7\% heterossexuais (GGB, 2017).

Quanto à idade das vítimas, predominaram assassinatos e mortes na faixa etária de 18 a 25 anos (32,9\%), sendo que 41,2\% se encontravam entre 26 e 40 anos, na flor da idade produtiva; 5,7\% eram menores de 18 anos. Em 1,9\% das mortes as vítimas correspondiam à terceira idade: o mais idoso tinha 75 anos.

Em relação à cor das vítimas de LGBTIfobia, constata-se a mesma regularidade dos anos anteriores, predominando os brancos (66\%), seguidos por $27 \%$ de pardos e $7 \%$ de negros. 
Quanto ao perfil racial por categoria sexológica, observa-se leve superioridade de transexuais e travestis negras (38\%), seguidas pelos gays (31\%) e pelas lésbicas (21\%). Cai por terra, portanto, o mito de que "a carne mais barata no mercado é a carne negra", já que $61 \%$ das trans, em sua maioria profissionais do sexo, foram identificadas nas reportagens policiais ou nas fotos dos jornais como brancas; $7 \%$ eram negras.

Embora, o relatório do GGB de 2018 ainda não tenha sido publicado, o site já apresenta alguns dados, como por exemplo, a média de idades dos indivíduos LGBTI assassinados 27 anos para pessoas trans e 38 anos para gays: 27,7 anos corresponde à idade média das pessoas trans e 28 anos das lésbicas, enquanto a média dos gays equivale a 38,1 anos e a de bissexuais é de 42,6 anos ${ }^{3}$. Além disso, o GGB (2018) contabilizou um total de 372 mortes $^{4}$ no ano.

As mortes ocorridas ao longo dos últimos 5 anos (2014 a 2018), como ilustra o Gráfico 1, demonstram que a sociedade contemporânea tem sido marcada por uma crise de respeito aos direitos humanos, à intolerância e à violência.

Gráfico 1 - Violência letal contra pessoas LGBTI no Brasil (2014-2018)

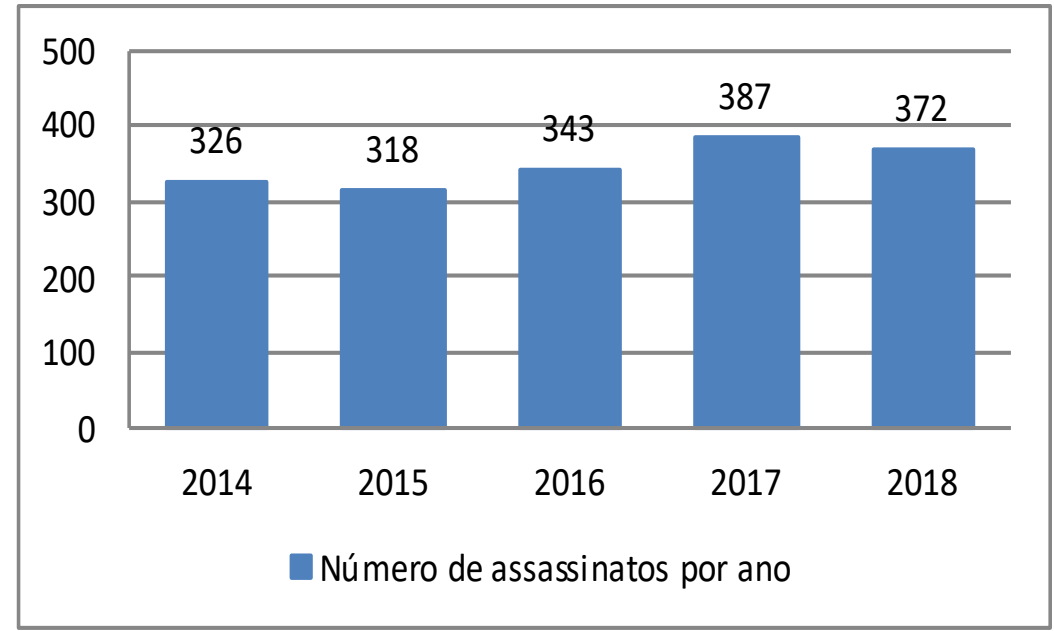

Fonte: Elaborado pelas autoras.

Além dos dados de violência letal contra a população LGBTI aqui apresentados, outros tipos de violência que decorrentes de preconceito/discriminação de identidade de gênero e orientação sexual não estão incluídas no relatório, como, por exemplo, tentativa de homicídio, lesão corporal, crimes contra a honra (injúria calúnia e difamação) e outras condutas tipificadas.

3 Esses dados foram levantados a partir de uma amostra com 2.730 pessoas (GGB, n.d.).

4 Esses dados são atualizados diariamente em GGB (n.d.). 
Esses números provocam uma reflexão em torno da violência letal, elemento que deve ser considerado efeito da LGBTIfobia da sociedade e do Estado.

\section{Mas o que é LGBTIfobia?}

A noção de homofobia foi desenvolvida nos anos 1970; estava inicialmente relacionada a um medo irracional da homossexualidade (Mason, 2002). A partir de então, diversos autores conceituam a homofobia (Borrillo, 2010; Espejo, 2012), outros preferem denominá-la preconceito sexual (Herek, 2004) ${ }^{5}$. No entanto, não entramos, aqui, nos debates conceituais sobre o termo.

A LGBTIfobia e o preconceito sexual podem ser entendidos como as atitudes hostis contra gays, lésbicas, bissexuais, travestis, transexuais, pessoas intersexo ou mesmo contra heterossexuais que simpatizem com indivíduos LGBTI.

Daniel Borrillo (2010, p. 13) explica que "do mesmo modo que a xenofobia, o racismo ou o antissemitismo, a homofobia é uma manifestação arbitrária que consiste em designar o outro como contrário, inferior ou anormal”.

Considerada um fenômeno complexo e variado (Borrillo, 2010), a homofobia pode ter uma forma sutil (Espejo, 2012), também denominada homofobia simbólica (Bourdieu, 2010), e ter uma forma mais gravosa, com o intuito de exterminar o outro, como no caso da Alemanha nazista (Borrillo, 2010).

Muitas vezes a homofobia é tolerada na esfera íntima privada, mas, quando reivindica status equivalente à heterossexualidade, torna-se intolerável. Pois a homofobia também se manifesta no medo de que esse status seja reconhecido.

A esse respeito, Borrillo (2010, p. 17) afirma que "a homofobia é o medo de que a valorização dessa identidade seja reconhecida; ela se manifesta, entre outros aspectos, pela angústia de ver desaparecer a fronteira e a hierarquia da ordem heterossexual".

Assim, a homofobia significa uma aversão, preconceito que algumas pessoas possuem em relação às pessoas homossexuais, lésbicas, bissexuais, transexuais e intersexos.

Cabe ressaltar que esse sentimento hostil desumaniza os indivíduos e fere a dignidade, assim como a personalidade dessas pessoas, uma vez que a sexualidade é algo que integra a própria condição humana (Dias, 2002).

As formas de manifestação da homofobia são diversas. Aqui, consideramos dois aspectos da homofobia, que, segundo Borrillo (2010), divide-se em dimensão pessoal e dimensão cultural, ou, para Espejo (2012), dimensão psicológica e dimensão social.

$5 \quad$ A pesquisa de Herek (2004) indica que essa forma de violência deve ser entendida como um preconceito, pois o termo homofobia pressupõe que as respostas negativas à população LGBTI são fundadas no medo patológico e irracional (fobia) e que nem sempre essas atitudes derivam do medo, mas sim do preconceito. 
O termo "homofobia" designa, assim, dois aspectos diferentes da mesma realidade: a dimensão pessoal, de natureza afetiva, que se manifesta pela rejeição dos homossexuais; e a dimensão cultural, de natureza cognitiva, em que o objeto da rejeição não é o homossexual enquanto indivíduo, mas a homossexualidade como fenômeno psicológico e social. Essa distinção permite compreender melhor uma situação bastante disseminada nas sociedades modernas que consiste em tolerar e, até mesmo, em simpatizar com os membros do grupo estigmatizado; no entanto, considera inaceitável qualquer política de igualdade a seu respeito (Borrillo, 2010, p. 22).

Infere-se da citação acima que a homofobia pessoal tem natureza afetiva e refere-se à rejeição dos homossexuais, enquanto a homofobia cultural tem natureza cognitiva, advinda de raízes sociais, culturais e políticas, onde não é a pessoa homossexual o alvo da hostilidade, mas a homossexualidade em si, como forma da diversidade relativa à orientação sexual.

Nesse sentido, Roger Raupper Rios (2009) afirma que a dimensão subjetiva desencadeadora da homofobia, qual seja, medo aversão e ódio, resulta em desprezo pelos homossexuais. Já a dimensão cultural, social ou política dessa manifestação discriminatória, devido à institucionalização da heterossexualidade como norma, acarreta a abjeção de outras manifestações da sexualidade humana (Rios, 2009).

A homofobia cultural é aquela "instalada na cultura que consagra o regime de exclusão de homossexuais". Incluindo as "violações dos direitos humanos destas pessoas, muitas vezes, inclusive, são desconhecidas por várias pessoas e organizações nacionais e internacionais que se dedicam à defesa e promoção de direitos humanos" (Espejo, 2012). Essa prática segregacionista e de exclusão devido a orientação sexual e identidade de gênero é considerada heterossexismo.

Esse sistema é compreendido como a consequência psicológica de uma representação social que, outorga a exclusividade da normalidade à identidade heterossexual, fomentando indiferença, desprezo e desconsideração de uma parte da sociedade em relação a todas as pessoas que não se encaixam no modelo de referência. O heterossexismo deve ser denunciado e combatido com a mesma veemência usada contra o racismo ou o antissemitismo (Borrillo, 2010).

Do mesmo modo que o heterossexismo, a heteronormatividade também é um dos elementos propulsores da homofobia. Criado por Michael Warner, o termo heteronormatividade pode ser entendido como ideia/axioma de que a heterossexualidade é a única orientação sexual "normal". Para ele, a heteronormatividade pode ser entendida como "instituições, estruturas de compreensão e orientações práticas que não apenas fazem com que a heterossexualidade pareça coerente", sendo vista como um estado natural, projetando-se como objetivo ideal ou moral (Berlant \& Warner, 1998, p. 548). 
Logo, a diferença entre heterossexismo e a heteronormatividade é que o primeiro conceito se refere a um sistema ideológico que discrimina, estigmatiza e nega todas as práticas não heterossexuais (Herek, 2004), enquanto o outro enquadra todas as relações, incluindo as homoafetivas dentro de um padrão binário, que sistematiza atitudes, posturas e desejos conforme a referência do relacionamento entre pessoas heterossexuais.

Desse modo, podemos compreender a LGBTIfobia como uma forma de violência contra a diversidade sexual, que alimenta as desigualdades de gênero, fere a dignidade e põe em risco a condição humana da população LGBTI, o que se expressa em aversão, intolerância, preconceito, discriminação e tantas outras formas de violência (física, patrimonial, psicológica).

Outrossim, como enfatiza Rita Segato (2014, p. 357, tradução nossa), a violência não deve ser compreendida como dispersa, esporádica e anômala como a mídia apresenta, mas "temos que perceber a sistematicidade dessa gigantesca estrutura que liga os elos aparentemente muito distantes da sociedade e aprisiona a própria democracia representativa".

Diante dessa problemática, é imprescindível a implementação de políticas públicas que visem ao enfrentamento da violência, principalmente aquelas ligadas a ideologias heterossexistas (Borrillo, 2010; Herek, 2004; Welzer-Lang, 2001) ${ }^{6}$ e heteronormativas (Berlant \& Warner, 1998).

\section{Em busca de soluções}

Embora a violência seja um fato humano e social que sempre esteve presente na sociedade, ela não faz parte da natureza humana, sendo considerada um fenômeno biopsicossocial em que sua complexidade dinâmica emerge na vida em sociedade (Minayo, 1994). Rita Segato (2003) afirma que a violência tem dinâmicas psíquicas, sociais e culturais, além disso, deve ser compreendida como um anúncio, ou seja, a violência é uma comunicação? .

Partindo do pressuposto de que a violência é uma forma de comunicação, é preciso utilizar estratégias e ferramentas de comunicação não violenta na desconstrução

$6 \quad$ Heterossexismo "é a discriminação e a opressão baseada em uma distinção feita a propósito da orientação sexual. O heterossexismo é a promoção incessante, pelas instituições e/ou indivíduos, da superioridade da heterossexualidade e da subordinação simulada da homossexualidade. O heterossexismo toma como dado que todo mundo é heterossexual" (Welzer-Lang, 2001, pp. 467).

7 Slavoj Zizek (2009) também corrobora esse entendimento ao afirmar que a violência assume a forma de linguagem. $\mathrm{O}$ autor classifica a violência em dois tipos: violência objetiva e violência subjetiva. Esta última é o tipo visível, que também traz consigo dois tipos objetivos de violência. Diferente da violência objetiva, que é entendida como sistêmica, fruto do funcionamento dos sistemas econômicos e políticos, tal violência "não pode ser atribuída a indivíduos concretos e às suas 'más' intenções, mas é puramente 'objetiva', sistêmica, anônima” (Zizek, 2009, p. 24). 
da LGBTIfobia, desse modo, o preconceito sexual, como fenômeno social, pode ser desconstruído a partir de diálogo, conversação, educação.

Diversos autores, a exemplo de Borrillo (2010) e Rios (2009) sinalizam que a educação é a melhor alternativa para combater a homofobia. A educação desempenha um importante papel na desconstrução e desmitificação do preconceito, auxiliando na compreensão de direitos humanos e direitos de igualdade independentemente da orientação sexual e identidade de gênero.

Os números ao longo dos últimos 5 anos, quais sejam, 326, 318, 343, 387 e 372, representam um total de 1.746 mortes de indivíduos LGBTI no Brasil, sem contar os números de suicídios que o heterossexismo e a heteronormatividade suscitam e os casos de subnotificação, que só contribuem para o processo de invisibilização desses sujeitos (Menezes, 2018).

Merece destaque o fato de que esse é um quadro de violência letal, não incluindo os inúmeros casos de violência que ocorrem todos os dias com a população sexodiversa, sejam os notificados ou os subnotificados, uma vez que muitos indivíduos não registram ocorrências por medo ou outro motivo. A falta de capacitação continuada dos profissionais que atendem à população vítima de violência LGBTIfóbica também é um fator determinante para a subnotificação de casos de violência (Menezes, 2018).

Apesar da intensificação desse quadro de violência, não existe uma lei que criminalize a homofobia, além disso, a tentativa da criação de uma lei desse porte no país foi frustrada em 2014, quando houve arquivamento do Projeto de Lei da Câmara (PLC) n. 122/2006, que almejava a criminalização de uma série de condutas resultantes de discriminação e/ou preconceito de gênero, orientação sexual e identidade de gênero.

Por outro lado, embora a existência de uma lei que estabeleça mecanismos de combate/prevenção às diversas formas de violência experimentadas pelas pessoas LGBTI se mostra necessária ${ }^{8}$, é preciso pensar em outras maneiras de solucionar os conflitos de modo que haja a possibilidade de mudança de condutas, com o intuito de promover a pacificação social e a qualidade dos relacionamentos entre os indivíduos, visto que a desconstrução do preconceito não pode ser viabilizada por meio da força bruta ou pela punição normativa isolada, pelo contrário, o uso de medidas punitivas apenas agrava "atitudes discriminatórias".

Nesse sentido, é preciso implementar novas formas de solução de conflitos, haja vista que a mera penalização da conduta criminosa motivada pela LGBTIfobia, sem que haja uma

$8 \quad$ Merece destaque o fato de que, no Brasil, existem leis para a proteção de negros e mulheres no âmbito penal, por exemplo, a Lei n. 7.716/1989, alterada pela Lei n. 12.288/2010 (Estatuto da Igualdade Racial), que define os crimes resultantes de preconceito de raça ou de cor, e também a Lei n. 11.340/2006 (Lei Maria da Penha), que cria mecanismos para coibir a violência doméstica e familiar contra a mulher. No entanto, inexistem leis que coíbam as atitudes discriminatórias e/ou estabeleçam agravantes no caso da prática de crimes já existentes, porém, motivados por preconceito/discriminação de identidade de gênero e orientação sexual. Esse quadro pode ser considerado reflexo de uma sociedade heteronormativa. 
reflexão por parte do ofensor e da comunidade, em nada contribui para construção social em relação à LGBTIfobia como produtora dessas violências.

O relatório do Alto Comisionado de las Naciones Unidas para los Derechos Humanos (ACNUDH, 2015) apresentou recomendações aos Estados para combater atos de violência e discriminação contra indivíduos com base em sua orientação sexual e identidade de gênero.

Entre as recomendações estão a promulgação de leis sobre crimes motivados por preconceitos que estabeleçam homofobia e transfobia como fatores agravantes para a determinação de penalidades e a investigação sem demora e exaustiva dos incidentes de violência motivados por ódio e tortura de pessoas LGBTI, bem como exigir responsabilidade dos perpetradores e proporcionar reparação às vítimas (ACNUDH, 2015).

Além disso, recomendou coleta, registro e publicação dos dados sobre o número e os tipos de incidentes registrados, garantindo a segurança dos reclamantes; proibição do incitamento ao ódio e à violência com base na orientação sexual e identidade de gênero; e responsabilização daqueles que proferem tal discurso de ódio (ACNUDH, 2015).

A capacitação dos profissionais responsáveis pela aplicação da lei e dos juízes por meio de abordagens sensíveis ao gênero para abordar as violações motivadas pela orientação sexual e identidade de gênero também faz parte dessas recomendações.

Igualmente, a CIDH reconhece a obrigação estatal de prevenir a violência, seja via coleta de dados, adoção de medidas legislativas para prevenir a violência (a exemplo da proteção legal reforçada diante da violência por preconceito, adoção de legislação que proteja e reconheça os direitos das pessoas e garantia de que as leis não discriminem ou reforcem a violência por preconceito) e a erradicação do estigma e dos estereótipos (CIDH, 2015).

A prevenção da violência em contextos específicos (prevenção da violência por forças de segurança do Estado, prevenção da violência no setor da saúde, prevenção da violência no setor educacional) também deve ser prioridade do Estado no combate à violência, assim como a obrigação estatal de investigar, julgar e punir crimes cometidos contra as pessoas LGBTI, entre outras medidas (CIDH, 2015).

No Brasil, existem diversas organizações sociais LGBTI $^{9}$ que atuam contra a homofobia, visando a garantir/proteger os direitos da população LGBTI. O apoio a essas ONGs também é uma medida que deve ser adotada para contribuir no fortalecimento da rede de apoio social, assim como mobilizar a comunidade LGBTI na busca de seus direitos.

Também se deve combater a homofobia institucional, que alimenta o heterossexismo e a heteronormatividade. No Brasil, o governo federal se posiciona em defesa da população sexodiversa via campanhas e espaços de denúncia:

$9 \quad$ Algumas dessas ONGs são: a) Associação Brasileira de Lésbicas, Gays, Bissexuais, Travestis e Transexuais (ABGLT); 
A postura do governo federal marca uma posição de defesa da comunidade LGBT.

O Estado oferece espaços de denúncia contra o preconceito, inscrevendo-o em uma posição de ilegalidade, já que sua prática pode resultar em denúncias e ações legais por parte da esfera governamental na defesa da comunidade LGBT. Nos recortes "ao se sentir ameaçado(a), ligue pra gente", "se você sofrer ou presenciar algum tipo de violência ou discriminação, denuncie" e "disque 100" (Figura 1), temos o discurso oficial marcando uma linha voltada para receber denúncias de homofobia, indicando a preocupação do governo com essa forma de violência, não qualquer tipo de violência, mas uma que é motivada por um ódio específico (Bastos, Garcia, \& Sousa, 2017, p. 17).

No entanto, a realidade se mostra destoante desse discurso. Os elevados índices de violência e a falta de uma lei que criminalize a homofobia ${ }^{10}$ demonstram que o Estado compactua com os ideais desses praticantes, pois, embora revestido de um discurso protecionista, não garante os direitos da população LGBTI. É preciso refletir se o governo brasileiro, em uma perspectiva da homofobia institucional, coaduna com uma política que deixa morrer a população LGBTI.

\section{Considerações finais}

O enfrentamento da violência contra a diversidade sexual é um enorme desafio da atualidade, pois a violência que vem se praticando coloca em risco os direitos fundamentais da população LGBTI e ameaça os direitos humanos desses indivíduos.

Em suas múltiplas dimensões, a violência, seja ela simbólica ou física, fere a dignidade de todas as pessoas que compõem a população sexodiversa, colocando em evidência a necessidade de garantir e efetivar direitos que visem a reduzir a violência que a heteronormatividade e o heterossexismo produzem.

A falta de uma educação voltada aos direitos humanos em muito contribui com o preconceito existente no Brasil - considerado o país que mais mata a população LGBTI no mundo. Esse é um problema político que não deve ser visto de forma isolada, mas de maneira interseccional, onde a desigualdade social, sexual e de gênero também fazem parte desse diagnóstico.

Mães pela Diversidade; Movimento D’Ellas; Casa 1 - São Paulo; b) Casa Nem e Grupo Arco-Íris -Rio de Janeiro; c) Grupo Gay da Bahia (GGB) - Bahia; d) Casa Amor; Associação das Travestis Unidas na Luta pela Cidadania - Sergipe; e) Instituto Boa Vista; Associação em Defesa dos Direitos Humanos com Enfoque na Sexualidade (Adeh) - Santa Catarina; entre outras (Catraca Livre, 2017).

10 É certo que a criminalização da homofobia não vai acabar com essa forma de violência, mas, contribuirá na padronização das ocorrências policiais e de outros órgãos públicos, evidenciando dessa maneira a realidade das violências contra LGBT. 
Os dados vislumbrados ao longo dessa reflexão são assustadores, pois indicam que a intolerância, o desrespeito, o preconceito e a discriminação são latentes na sociedade brasileira contemporânea.

A reflexão em torno dos dados apresentados se mostra urgente e necessária para a busca de soluções e mecanismos de enfrentamento da violência LGBTIfóbica. É preciso perceber cada LGBTIcídio como um ataque a toda a sociedade e, consequentemente, como um enfraquecimento do próprio Estado de direito.

Chegou o momento em que, parafraseando Segato (2016), precisamos nos enxergar no espelho da rainha má e compreender nossa posição no mundo:

- Espelho, espelho meu, somos uma sociedade preconceituosa e LGBTIfóbica?

- Ocupamos o primeiro lugar no ranking dos países que mais matam indivíduos LGBTI?

Assim, descortinamos o véu da ignorância para que venha a questão conclusiva:

- $O$ que fazer e como fazer para combater a LGBTIfobia?

\section{Referências bibliográficas}

Alto Comisionado de las Naciones Unidas para los Derechos Humanos. (2015). A/HRC/29/23. Discriminación y violencia contra las personas por motivos de orientación sexual e identidad de género. Recuperado de https://www.ohchr.org/EN/HRBodies/HRC/RegularSessions/Session29/Pages/ ListReports.aspx

Bastos, G. G., Garcia, D. A., \& Sousa, L. M. A. (2017). A homofobia em discurso: direitos humanos em circulação. Linguagem em (Dis)curso, 17(1), 11-24.

Berlant, L., \& Warner, M. (1998). Sex in public. Critical Inquiry, 24(2), 547-566.

Borrillo, D. (2010). História e crítica de um preconceito. Belo Horizonte, MG: Autêntica.

Bourdieu, P. (2010). O poder simbólico. Rio de Janeiro, RJ: Bertrand Brasil.

Catraca Livre. (2017, 17 de maio). ONGs e projetos LGBTs para você ajudar (e conhecer) em sua cidade. Recuperado de https://catracalivre.com.br/cidadania/ongs-e-projetos-Igbts-para-voce-ajudar-e-conhecer-em-sua-cidade/

Cerqueira, D., Lima, R. S., Bueno, S., Neme, C., Ferreira, H., Coelho, D. ... Merian, F. (Coords.). (2018). Atlas da Violência 2018. Rio de Janeiro, RJ: Instituto de Pesquisa Econômica Aplicada.

Comissão Interamericana de Direitos Humanos. (2015). Violência contra pessoas lésbicas, gays, bissexuais, trans e intersexo nas Américas. Recuperado de http://www.oas.org/pt/cidh/docs/pdf/ ViolenciaPessoasLGBTI.pdf

Comissão Interamericana de Direitos Humanos. (2012). CIDH condena ataque y asesinato por orientación sexual percibida en Brasil. Recuperado de http://www.oas.org/es/cidh/prensa/comunicados/2012/084.asp 
Comissão Interamericana de Direitos Humanos. (2012). CIDH condena asesinato de adolescente gay en Brasil. Recuperado de http://www.oas.org/es/cidh/prensa/comunicados/2012/089.asp

Comissão Interamericana de Direitos Humanos. (2012). CIDH condena asesinato de dos mujeres trans en Brasil. Recuperado de http://www.oas.org/es/cidh/prensa/comunicados/2012/079.asp

Dias, M. B. (2002). Liberdade sexual e direitos humanos. In Anais do III Congresso Brasileiro de Direito de Família: Família e cidadania. IBDFAM/OAB-MG, Belo Horizonte (pp. 85-86).

Espejo, J. C. (2012). Componentes ideológicos de la homofobia. Límite: Revista Interdisciplinaria de Filosofía y Psicología, 7(26), 85-106.

Grupo Gay da Bahia. (2014). Relatório 2014. Recuperado de https://homofobiamata.wordpress.com/ relatorios/2014-2/

Grupo Gay da Bahia. (2015). Relatório 2015. Recuperado de https://homofobiamata.wordpress.com/ relatorios/2015-2/

Grupo Gay da Bahia. (2016). Relatório 2016. Recuperado de https://homofobiamata.wordpress.com/ relatorios/2016-2/

Grupo Gay da Bahia. (2017). Relatório 2017. Recuperado de https://homofobiamata.wordpress.com/ relatorios/2017-2/

Grupo Gay da Bahia. (2018). Relatório 2018. Recuperado de https://homofobiamata.wordpress.com/ homicidios-de-lgbt-no-brasil-em-2018/

Grupo Gay da Bahia. (n.d.). Brasil campeão mundial de mortes por LGBTfobia!! Recuperado de https://homofobiamata.wordpress.com/

Herek, G. M. (2004). Beyond "homophobia": thinking about sexual prejudice and stigma in the twenty-first century. Sexuality Research \& Social Policy, 1(2), 6-24.

Instituto Brasileiro de Geografia e Estatística. (2018). Tábuas completas de mortalidade. Rio de Janeiro, RJ: Autor.

Mason, G. (2002). The spectacle of violence: homophobia, gender and knowledge. London, England: Routledge.

Menezes, M. S. (2018) Os não recomendados: a violência contra a população LGBT em Sergipe. Aracaju, SE: Edise.

Minayo, M. C. D. S. (1994). Violência social sob a perspectiva da saúde pública. Cadernos de Saúde Pública, 1994(10), S7-S18.

Organización de los Estados Americanos. (2012a, 6 de julio). CIDH condena asesinato de dos mujeres trans en Brasil. Recuperado de http://www.oas.org/es/cidh/prensa/comunicados/2012/079.asp Organización de los Estados Americanos. (2012b, 11 de julio). CIDH condena ataque y asesinato por orientación sexual percibida en Brasil. Recuperado de http://www.oas.org/es/cidh/prensa/comunicados/2012/084.asp 
Organización de los Estados Americanos. (2012c, 16 de julio). CIDH condena asesinato de adolescente gay en Brasil. Recuperado de http://www.oas.org/es/cidh/prensa/comunicados/2012/089.asp Rios, R. R. (2009). Homofobia na perspectiva dos direitos humanos e no contexto dos estudos sobre preconceito e discriminação. In R. D. Junqueira (Org.), Diversidade sexual na educação: problematizações sobre a homofobia nas escolas (pp. 53-83). Brasília, DF: Ed. MEC.

Segato, R. L. (2003). Las estructuras elementales de la violencia. Ensayos sobre género entre la antropología, el psicoanálisis y los derechos humanos. Bernal, Argentina: Universidad de Quilmes.

Segato, R. L. (2014). Las nuevas formas de la guerra y el cuerpo de las mujeres. Sociedade e Estado, 29(2), 341-371.

Segato, R. L. (2016). Frente al espejo de la reina mala. Docencia, amistad y autorización como brechas decoloniales en la universidad. Versión. Estudios de Comunicación y Política, 2016(37), 201-216.

Welzer-Lang, D. (2001). A construção do masculino: dominação das mulheres e homofobia. Estudos Feministas, 9(2), 460-482.

Zizek, S. (2009). Sobre la violencia: seis reflexiones marginales (Vol. 1). Buenos Aires, Argentina: Paidós.

\section{Para citar este artigo:}

\section{Norma A - ABNT}

SANTOS, K. A. A.; SPOSATO, K. B. Um olhar sobre a violência LGBTIfóbica no Brasil. Conhecer: Debate entre o Público e o Privado, n. 22, p. 8-21, 2019.

\section{Norma B - APA}

Santos, K. A. A., \& Sposato, k. B. (2019). Um olhar sobre a violência LGBTIfóbica no Brasil. Conhecer: Debate entre o Público e o Privado, 2019(22), 8-21.

\section{Norma C - Vancouver}

Santos KAA, Sposato KB. Um olhar sobre a violência LGBTIfóbica no Brasil. Conhecer: Debate entre o Público e o Privado [Internet]. 2019 [cited Apr 22, 2019];(22):8-21. Available from: https://revistas. uece.br/index.php/revistaconhecer/article/view/1014 